\title{
MÉTODO DE CUSTEIO BASEADO EM ATIVIDADES E TEMPO: ESTUDO DE CASO EM UM ESCRITÓRIO DE CONTABILIDADE
}

\author{
TIME DRIVEN ACTIVITY BASED COSTING (TDABC): CASE STUDY IN AN ACCOUNTING \\ OFFICE
}

\section{Caroline Fabrin}

Faculdade de Integração do Ensino Superior do Cone Sul - FISUL, RS, Brasil, carolfabrin90@gmail.com

\section{Marcelo Juarez Vizzotto}

Faculdade de Integração do Ensino Superior do Cone Sul - FISUL, RS, Brasil, marcelovizzotto.mv@gmail.com

\section{Lauri Paulus}

Faculdade de Integração do Ensino Superior do Cone Sul - FISUL, RS, Brasil, lauri.paulus@ifrs.edu.br

Resumo: A contabilidade de custos, através de seus métodos de custeio, possibilita que as empresas apurem seus custos de produção, de comercialização ou de prestação de serviços. Neste contexto, o objetivo desta pesquisa foi analisar a aplicabilidade do método de custeio baseado em atividades e tempo (time driven activity based costing TDABC). Para tanto, foi realizado um estudo exploratório e descritivo com abordagem quantitativa caracterizandose como um estudo de caso, sendo aplicado em um escritório prestador de serviços contábeis. Como resultado, após uma análise detalhada dos gastos da empresa em estudo, foi possível aplicar o TDABC, utilizando o tempo como fator principal para a distribuição dos custos incorridos para prestação de serviços. Como implicação desses achados de pesquisa, o estudo contribui para uma melhor compreensão dos custos e para confirmar a viabilidade do método sugerido, pois o mesmo possibilita a definição das atividades executadas por departamento, bem como a mensuraçáo, de forma precisa, dos custos de cada um dos clientes.

Palavras-chave: TDABC. Prestação de serviços. Contabilidade de custos.

Abstract: Cost accounting, through its costing methods, enables companies to calculate their production, marketing or service costs. In this context, the objective of this research was to analyze the applicability of the time driven activity based costing (TDABC) method. To this end, an exploratory and descriptive study with a quantitative approach was performed, characterized as a case study, being applied in an office providing accounting services. As a result, after a detailed analysis of the expenses of the company under study, it was possible to apply the TDABC, using time as the main factor for the distribution of costs incurred to provide services. As an implication of these research findings, the study contributes to a better understanding of costs and confirms the feasibility of the suggested method, as it enables the definition of the activities performed by department, as well as the accurate measurement of the costs of each department. one of the clients.

Keywords: TDABC. Services provision. Cost accounting. 


\section{INTRODUÇÃO}

A partir da Revolução Industrial passou-se a utilizar a contabilidade de custos para avaliar os estoques e para identificar, mensurar e informar os custos dos produtos e dos serviços prestados. É um instrumento importante no controle e suporte nas tomadas de decisóes. A contabilidade de custos tem por objetivo planejar, classificar, alocar, organizar e registrar os custos dos produtos (CREPALDI, 2010).

Os métodos de custeio são ferramentas utilizadas para determinar os custos da produção e dos serviços prestados e, assim, conseguir incorporá-los ao seu preço de venda. Cada empresa deve analisar a sua situação para descobrir o melhor método a ser utilizado no seu ramo de atividade. Como exemplos de métodos de custeio citam-se: o Método de Custeio Variável, o Método de Custeio por Absorção e também o Método do Custeio Baseado em Atividades (ABC) (PADOVEZE, 2013).

O custeio por absorção é conhecido por ser o tradicional método de custeio, onde se alocam os custos de cada uma das fases de produção aos seus produtos. Cada produto fabricado, ou em produção, já vai recebendo a parcela de custo que lhe cabe naquele momento, e as despesas geradas no processo de produção já são diretamente lançadas como despesas do período na Demonstração do Resultado do Exercício (DRE) (MARTINS, 2018; CORONETTI; BEUREN; SOUZA, 2012).

Já o custeio variável é o método em que os produtos só terão a inclusão dos custos que forem da produção, ou seja, os variáveis. Os custos fixos, por não serem utilizados pela produção, são lançados diretamente no resultado do exercício como custos (despesas) do período. Esse método não é aceito pela legislação fiscal, portanto é utilizado apenas como ferramenta gerencial (MARTINS, 2018; MEGLIORINI, 2012).

$\mathrm{O}$ método $\mathrm{ABC}$ vem para melhorar, aperfeiçoar e possibilitar a análise de custos tradicional. No método $\mathrm{ABC}$, os custos são separados e consumidos pelas atividades e não pelos produtos fabricados. Os custos são consequências das atividades da fabricação ou comercialização (CREPALDI, 2010; MEGLIORINI, 2012; NAKAGAWA, 2012).

Tem-se, ainda, o método de custeio Time Driven Activity Based Costing (TDABC), o qual surgiu como uma nova abordagem ao já conhecido método ABC. Seu objetivo é fornecer uma opção simples e prática na determinação dos custos, utilizando-se do tempo consumido pelas atividades para alocar os custos aos objetos de custeio. Ele demanda apenas o custo de fornecimento dos recursos da atividade e o tempo para a sua execução (SCHMIDT; LEAL; SANTOS, 2011; RODRIGUES; PINHO, 2017).

Com a crescente demanda por serviços, o que antes era irrelevante na contabilidade das prestadoras passou a ser utilizada principalmente nas tomadas de decisão. Pode-se dizer que hodiernamente a contabilidade de custos para as empresas de prestação de serviço tem a função idêntica à de uma empresa industrial (MARTINS, 2018).

Destaca-se que a empresa prestadora de serviços tem, assim como uma industrial e comercial, uma série de gastos para realizar as suas atividades, como por exemplo a compra de materiais de escritório, folha de pagamento, pagamento de impostos e taxas, entre outros. Tem também as despesas relacionadas à administração da empresa e à geração de receitas (MEGLIORINI, 2012). 
Por outro lado, em uma pesquisa na base de dados Spell Scientific Periodicals Electronic Library verificou-se que o método de custeio baseado em atividades e tempo foi pouco explorado, tendo apenas cinco trabalhos publicados. Além do mais nenhum deles foi realizado em empresas prestadoras de serviços contábeis, e essas têm como principal custo a mão de obra, a qual deve ser alocada ao objeto de custo por meio do tempo. Dessa forma, o objetivo deste estudo é analisar a aplicabilidade do método de custeio baseado em atividades e tempo (TDABC) em escritório de prestação de serviços contábeis fazendo o custeamento dos serviços e medindo sua aplicaçáo em dez clientes. A escolha pelo objeto do estudo se deu pelo fato de que a empresa não realiza nenhum controle gerencial do custeamento dos seus serviços.

Após apresentada a importância do estudo se mostra a estrutura deste artigo, composto por cinco partes, sendo esta a primeira, com a contextualizaçáo do assunto e o objetivo da pesquisa. A segunda parte traz a revisão da teoria sobre o tema. Na terceira parte a metodologia para realização da pesquisa empírica. A quarta parte foi destinada para apresentação e análise dos resultados. Já a quinta e última parte foi destinada para as considerações finais, apresentaçôes das limitaçôes do estudo e indicações de pesquisas futuras.

\section{REVISÃO BIBLIOGRÁFICA}

\subsection{Contabilidade de Custos (Histórico e Evolução)}

O primeiro propósito da Contabilidade de Custos foi o controle dos estoques e a apuração do lucro das empresas. Porém, com o passar do tempo e o crescimento das empresas, a Contabilidade de Custos foi aumentando sua importância, passando a ser conhecida e utilizada como uma ferramenta de gestão pelos administradores e sócios das empresas (BORNIA, 2010; MARTINS, 2018).

Para conceituar a contabilidade de custos, uma das formas é entendê-la como a atividade que coleta, recebe os dados, registra de forma organizada, analisa e os interpreta, produzindo as informaçóes para os departamentos gerenciais. Esta é uma técnica, e também uma função, utilizada para auxiliar o planejamento e o desempenho das atividades produtivas da empresa (CREPALDI, 2010; BRUNI; FAMÁ, 2014).

A literatura nos apresenta diversos tipos de métodos de custeio, que podem ser utilizados tanto para empresas do ramo industrial e comercial quanto para prestadoras de serviços. Cada um deles pode ser especificado por uma característica, por exemplo: o método $\mathrm{ABC}$ pode ser chamado de contemporâneo; o método variável pode ser considerado como o tradicional; e o de absorção simplesmente pode ser caracterizado como o que possui seçóes homogêneas (PADOVEZE, 2013; MEGLIORINI, 2012).

\subsection{Método de custeio TDABC - Time Driven Activity Based Costing}

Método que surgiu como uma nova abordagem ao método $\mathrm{ABC}$, com o objetivo de oferecer uma opçáo simples e prática na determinação dos custos e com a capacidade de utilizá-los nos processos, uma vez que o $\mathrm{ABC}$ apresentava alguns problemas e desvantagens como, por exemplo, busca de dados demorada, difícil validação dos dados apurados e o método não possuía mecanismos de atualização. 
Buscando então algumas melhorias, o método TDABC surgiu, em 1997, na empresa Wilson-Mohr, onde Steven Anderson o desenvolveu e aperfeiçoou (KAPLAN; ANDERSON, 2007; CONSORTE; UMPIERRE; BRUCHÊZ, 2015). O Quadro 1 demonstra as principais diferenças entre o Método ABC e o TDABC.

Quadro 1 - Principais diferenças entre o método ABC e o TDABC

\begin{tabular}{|c|c|}
\hline ABC & TDABC \\
\hline $\begin{array}{c}\text { Identifica as diferentes atividades. } \\
\text { do direcionador de recurso. }\end{array}$ & Identifica os departamentos. \\
\hline $\begin{array}{c}\text { Identifica o direcionador de atividade. } \\
\text { dimasto o custo total de cada departamento. }\end{array}$ \\
\hline $\begin{array}{c}\text { Determina a taxa de direcionador de atividade, } \\
\text { dividindo os custos totais da atividade pelo volume } \\
\text { prático. }\end{array}$ & $\begin{array}{c}\text { Calcula-se a capacidade prática de cada departamento } \\
\text { (apenas horas produtivas, excluindo férias, reuniões e } \\
\text { horas de treinamento). }\end{array}$ \\
\hline $\begin{array}{c}\text { Multiplica a taxa de direcionador de atividade pelo unitário de cada departamento, } \\
\text { consumo da atividade para traçar os custos. } \\
\text { capacidade prática (horas trabalhadas). }\end{array}$ & $\begin{array}{c}\text { Determina a estimativa do tempo para cada caso, com } \\
\text { base na equação de tempo para a atividade. }\end{array}$ \\
\hline
\end{tabular}

Fonte: Adaptado de Everart et al. (2008, apud MAZZUCO; WRONSKI; ZONATTO, 2017).

O método busca fornecer os dados mais corretos e com celeridade para a empresa obter as informações necessárias. Possibilita ainda mais flexibilidade nas atividades, de forma a identificar perfeitamente a lucratividade dos serviços. Utiliza-se do tempo consumido pelas atividades para alocar os custos aos objetos de custeio (SCHMIDT; LEAL; SANTOS, 2011; RODRIGUES; PINHO, 2017).

O TDABC desconhece a etapa de definir as atividades, suprimindo a necessidade de alocar os custos dos departamentos entre as atividades executadas. Também agrupa com facilidade as alteraçôes nas demandas de tempo em diferentes tipos de transaçôes, ou seja, não considera que os pedidos e transações sejam iguais e nem tenham o mesmo tempo no procedimento (KAPLAN; ANDERSON, 2007).

Podem ser observadas algumas vantagens no método de custeio TDABC, conforme os autores Kaplan e Anderson (2007) apresentam: i) é mais fácil e rápido para desenvolver um modelo preciso; ii) aproveita com eficácia os dados disponíveis; iii) direciona os custos de acordo com suas características; iv) pode ser processado todos os meses; v) torna visíveis as eficiências dos processos; vi) prevê a necessidade de recursos; vii) fornece informaçôes detalhadas; e, viii) é aplicável a diversos departamentos.

Como desvantagens do método, pode-se citar: existência de poucos estudos e materiais sobre a metodologia, exige muitas informaçóes para a construção das equações em que existe ainda uma certa dificuldade na definição dos cálculos de tempo onde os ambientes sejam instáveis e exige também o empenho e o envolvimento de funcionários para que o uso de sua metodologia seja eficaz (KAPLAN; ANDERSON, 2007).

Para a sua implantação, as empresas precisam analisar os seguintes fatores: o crescimento dos custos e das despesas indiretas, a concorrência no segmento e a diversificação de serviços, de processos e de clientes. O método demanda a estimativa de apenas duas variáveis para a sua aplicação: a) o custo de 
Método de Custeio Baseado em Atividades e Tempo...

fornecimento de recursos a uma atividade; e b) o tempo exigido para executá-la (KAPLAN; ANDERSON, 2007).

O primeiro cálculo do método refere-se à soma dos custos referentes aos recursos fornecidos a um processo ou departamento. Esta soma então é dividida pelo tempo utilizado para a execução do serviço. $\mathrm{O}$ resultado será a taxa do custo da capacidade, a qual aponta o custo em reais por minuto. Esta taxa poderá ser utilizada na alocação dos custos do departamento aos objetos por meio de estimativas de tempo da realização do serviço (KAPLAN; ANDERSON, 2007).

A seguir, fórmula da taxa de custo da capacidade, adaptada de Kaplan e Anderson (2007).

\section{Taxa do custo da capacidade $=\frac{\text { Custo da capacidade }}{\text { Capacidade prática dos recursos fornecidos }}$}

Após feita esta equação, pode ser efetuado o segundo passo que consiste em medir a capacidade necessária, ou seja, o tempo necessário para executar cada atividade. A principal característica encontrada que difere o método $\mathrm{ABC}$ do TDABC é que o método adaptado utiliza o tempo como principal direcionador dos custos (KAPLAN; ANDERSON, 2007).

\section{METODOLOGIA}

A fim de atingir os objetivos do presente trabalho, o estudo foi classificado como uma pesquisa descritiva e exploratória.

Descritiva pois a análise do estudo foi documental a partir dos demonstrativos da empresa, e também pelo levantamento dos dados que foram recolhidos de acordo com o preenchimento das planilhas referentes ao tempo necessário para realizar as atividades de cada departamento, por cliente.

A pesquisa descritiva tem como principal objetivo a descrição das características do estabelecimento. Pesquisa que trabalha com dados e fatos coletados de forma real, sem manipulaçóes, onde é necessário que se faça somente os registros, as análises e as conexôes dos fatos e dados (CERVO; BERVIAN; DA SILVA, 2007; GIL, 2019).

Caracterizada também como pesquisa exploratória, tem como objetivo desenvolver, esclarecer, definir objetivos e buscar mais informações sobre um determinado assunto de estudo. Permite um aprofundamento na análise dos dados e admite que se possa escolher a melhor técnica para evoluir e avançar na pesquisa. Através da pesquisa exploratória é mais fácil chegar ao objetivo do trabalho.

A pesquisa também tem abordagem quantitativa, pois esta aplica a quantificação em modalidades de coletas de informaçóes e no tratamento das mesmas, por meio de técnicas estatísticas. Tem por objetivo garantir a precisão dos resultados encontrados nas pesquisas procurando evitar possíveis distorçôes nas análises e em suas interpretações. É frequentemente aplicada a estudos descritivos, pois busca descobrir relaçôes entre variáveis e possíveis casualidades (RAUPP; BEUREN, 2014).

Quanto aos procedimentos técnicos, o presente trabalho tem como características o estudo de caso, que é aplicado em uma empresa de prestação de serviços contábeis na Serra Gaúcha. Caracterizado como um estudo intenso e cansativo, de objetivos com extenso e detalhado conhecimento. Pode ser 
utilizado o estudo de caso em pesquisas descritivas assim como em pesquisas exploratórias ou explicativas (GIL, 2017; SEVERINO, 2018).

Também como procedimento, foi realizada a pesquisa ação, que se justifica pelo fato de envolver a empresa pesquisada no estudo e os pesquisadores. E também, por investigar os fatos e dados da empresa formulando e desenvolvendo meios para resolver os problemas encontrados, procurando práticas de aprimoramento (SANTOS 2015; SEVERINO, 2018).

A pesquisa ação pode ser realizada para organizar objetivos em um estudo onde os autores orientam e organizam o mesmo de acordo com os meios que estão disponíveis. Ainda pode ser realizada em uma empresa, por exemplo, onde as partes interessadas (sócios, diretores) solicitam para organizar e sanar os problemas por meio de reuniôes. Ou ainda realizada em bairros, comunidades, com o intuito de realizar trabalhos à comunidade (GIL, 2017; THIOLLENT, 2011).

Os dados para a pesquisa foram obtidos através de coleta de dados por meio de análise documental, visto que se trata de um método ideal para reunir informaçôes necessárias para atender e solucionar os objetivos propostos. A coleta de dados é o passo seguinte após a escolha e a delimitação do tema, objetivos, a formulação do problema de pesquisa e da revisão bibliográfica (CERVO; BREVIAN; DA SILVA, 2007).

A análise documental nada mais é do que uma pesquisa com materiais que ainda não sofreram qualquer tipo de tratamento ou que possam ser reestruturados de acordo com os objetivos de cada pesquisa. Pode ser vista ainda como uma pesquisa com objetivos de coletar informaçóes que sejam úteis para a análise e o entendimento do problema proposto pelo trabalho. E para consegui-las devem ser analisados documentos que transmitam a realidade da empresa, documentos da rotina da mesma (MICHEL, 2014; GIL, 2019).

Os dados coletados através da planilha eletrônica (coleta do tempo utilizado por cada departamento para cada cliente), bem como os dados sobre todos os gastos, foram utilizados através do método de custeio TDABC. Assim, todos os gastos foram identificados e separados a fim de tornar possível a sua aplicação ao método de custeio sugerido. A coleta de dados refere-se à movimentação ocorrida no terceiro trimestre do exercício, sendo que trabalhou-se com a média de gastos. Ainda, diariamente os colaboradores da empresa anotavam o tempo de execução de cada atividade.

Além disso, foi possível calcular, seguindo as orientações de Kaplan e Anderson (2007) descritas no capítulo dois, de forma clara e precisa, os custos que cada cliente gera dentro de cada departamento e o total para a empresa prestadora de serviços contábeis da Serra Gaúcha.

\section{ANÁLISE DOS DADOS}

\subsection{Caracterização da empresa}

Empresa fundada no ano de 1999 por duas amigas e ex-colegas de faculdade do curso de Ciências Contábeis que tinham por objetivo empreender. Decidiram unir-se, formando uma sociedade e abrir um escritório, para prestar serviços na área contábil. Iniciaram as atividades atendendo pequenas empresas 
e fazendo serviços terceirizados em empresas de médio porte. Com o passar do tempo, mais empresas buscaram o escritório, que já se tornava referência neste ramo no seu município e em municípios próximos.

O objeto social é de prestação de serviços contábeis. O escritório possui uma carteira com 328 clientes entre ativos e inativos. Atende os mais variados ramos de atividades, como indústrias em geral, comércios, transportadoras, prestadores de serviços de diversas áreas.

O corpo funcional da empresa é composto por oito colaboradores, divididos por departamentos. Três colaboradores no departamento de Recursos Humanos (RH), três no departamento Fiscal e dois no departamento Contábil. Conta também com as duas proprietárias que contribuem com todos os departamentos.

\subsection{Identificação e classificação dos gastos}

Através da coleta dos dados realizada na empresa foram elaboradas planilhas com os custos e despesas, assim como elaborada a planilha com os bens do imobilizado e a depreciação mensal e anual.

\subsubsection{Custos diretos}

Os custos diretos, conforme Tabela 1, equivalem aos valores de salários dos oito colaboradores da empresa, mais os valores dos encargos onde estão vinculados os valores de FGTS, INSS, Férias, 130 Salário e IRRF. Como a empresa está dividida em três departamentos: Contábil, Fiscal e RH, classificou-se como diretos aqueles custos específicos de cada departamento.

Tabela 1 - Cálculo dos custos diretos

\begin{tabular}{l|r|r|r}
\hline \multicolumn{1}{c|}{ Custos Diretos } & \multicolumn{1}{c|}{ Contábil } & \multicolumn{1}{c|}{ Fiscal } & \multicolumn{1}{c}{ RH } \\
\hline Custo Salarial & $7.145,00$ & $4.337,00$ & $5.315,67$ \\
\hline FGTS & 775,83 & 476,00 & 644,14 \\
\hline INSS & $1.040,76$ & 608,79 & 815,98 \\
\hline Férias & $1.467,00$ & 925,33 & $2.143,00$ \\
\hline $13^{\circ}$ Salário & 0,00 & 0,00 & 0,00 \\
\hline IRRF & 531,93 & 78,23 & 131,70 \\
\hline Rescisões & 0,00 & $1.164,81$ & 0,00 \\
\hline Custos Totais & $10.960,52$ & $7.590,15$ & $9.050,49$ \\
\hline $\begin{array}{l}\text { Part. dos custos por } \\
\text { departamento no custo total }\end{array}$ & $\mathbf{4 0 \%}$ & $\mathbf{2 7 \%}$ & $\mathbf{3 3 \%}$ \\
\hline
\end{tabular}

Fonte: Elaborada pelos autores (2019).

Os custos salariais foram levantados com base no relatório mensal descritivo emitido pelo departamento de RH, o qual expressa os valores dos salários de cada colaborador e os encargos de cada folha. No mês de julho ocorreu uma rescisão de uma colaboradora do departamento contábil. Após a rescisão, a empresa optou por manter seu corpo de colaboradores com uma pessoa a menos. É importante destacar que os valores são a média dos custos diretos dos meses de junho, julho e agosto. 


\subsubsection{Custos indiretos}

Os Custos Indiretos da empresa estão listados na Tabela 2. Da mesma forma que os custos diretos se fez uma média de gastos dos meses de junho, julho e agosto. O pró-labore refere-se ao pagamento mensal das sócias da empresa. $\mathrm{O}$ aluguel pago é referente a três salas que a empresa utiliza para a prestação dos serviços. É possível verificar o item de Despesas Gerais, onde são apropriadas as despesas como o pagamento das taxas do conselho (CRC) e os pagamentos efetuados a sindicatos.

Tabela 2 - Custos fixos totais

\begin{tabular}{|c|c|}
\hline Recursos & Total (R\$) \\
\hline Pró-labore & $3.308,00$ \\
\hline Aluguel & $3.000,00$ \\
\hline Energia Elétrica & 767,05 \\
\hline Telefone & $1.061,83$ \\
\hline Material de Escritório & $2.558,33$ \\
\hline Despesas Gerais & $2.252,95$ \\
\hline Treinamento/Consultoria & $1.452,00$ \\
\hline Despesas com internet & 202,00 \\
\hline Sistemas & $2.099,00$ \\
\hline Condomínio & 780,00 \\
\hline Limpeza & 280,00 \\
\hline Táxi & 318,33 \\
\hline Total & $18.080,47$ \\
\hline
\end{tabular}

Fonte: Elaborada pelos autores (2019).

O item de treinamento/consultoria engloba todas as consultas que os colaboradores do escritório fazem com a empresa que presta serviços auxiliando em dúvidas de tributação ou normas. Engloba ainda os cursos que são propostos aos colaboradores e outros custos com eventos criados para os clientes.

O item sistemas refere-se ao pagamento da "locação" de dois sistemas, um que somente o departamento de RH utiliza e o outro sistema que o departamento Fiscal e Contábil utilizam. Dentro dos materiais de escritório encontram-se a compra de papel, papel serrilhado (para folha de pagamento), canetas, toner, envelopes, bobinas para calculadoras.

Dentro do item de custos com deslocamento encontram-se o valor pago a carros locados, táxis para se deslocar até os municípios onde os clientes se encontram, assim como serviços que precisam ser concluídos em órgãos públicos, como Receita Federal, Receita Estadual, Prefeituras.

A limpeza é paga referente à higienização e à limpeza do ambiente de trabalho, a qual é realizada uma vez por semana. Já os gastos com energia elétrica, telefone e condomínio são custos mensais que a empresa tem para a realização da prestação dos serviços.

A empresa não possuía a lista dos bens do ativo imobilizado completa em seu sistema. Portanto, para realizar a análise e o cálculo da depreciação, conforme Tabela 3, fez-se uma busca em todas as notas fiscais de compra de bens do ativo imobilizado. 
Método de Custeio Baseado em Atividades e Tempo...

Caroline Fabrin | Marcelo Juarez Vizzotto | Lauri Paulus

Tabela 3 - Depreciação

\begin{tabular}{|c|c|c|c|c|}
\hline Investimentos & Total (RS) & $\begin{array}{c}\text { Taxa } \\
\text { Anual de } \\
\text { Depreciação } \\
\%\end{array}$ & $\begin{array}{c}\text { Valor da } \\
\text { Depreciação } \\
\text { Anual (R\$) }\end{array}$ & $\begin{array}{c}\text { Valor da } \\
\text { Depreciação } \\
\text { Mensal (R\$) }\end{array}$ \\
\hline $\begin{array}{l}\text { Equipamentos } \\
\text { de Informática }\end{array}$ & $72.435,25$ & $20 \%$ & $14.487,05$ & 1207,25 \\
\hline $\begin{array}{l}\text { Máquinas e } \\
\text { Equipamentos }\end{array}$ & $16.903,30$ & $10 \%$ & $1.690,33$ & 140,86 \\
\hline $\begin{array}{l}\text { Móveis e } \\
\text { Utensílios }\end{array}$ & $34.938,50$ & $10 \%$ & $3.493,85$ & 291,15 \\
\hline Total & $124.277,05$ & & $19.671,23$ & $1.639,27$ \\
\hline
\end{tabular}

Fonte: Elaborada pelos autores (2019).

A determinação da parcela do cálculo de depreciação anual, utilizada para o cálculo do presente trabalho, foi aplicada conforme as taxas de depreciação admitidas pelo Brasil em conformidade com o regulamento do Imposto de Renda (BRASIL, s. d.).

Utilizou-se a taxa de $20 \%$ a.a. (vida útil de 5 anos) para os equipamentos de informática. E a taxa 10\% a.a. (vida útil de 10 anos) sobre o valor das máquinas e equipamentos e de móveis e utensílios.

\subsubsection{Despesas variáveis}

A Tabela 4 demonstra as despesas variáveis referentes aos três meses do estudo, as quais variam de acordo com o faturamento que a empresa atinge, com base sempre nos últimos 12 meses para o Simples. E para o ISS, o cálculo é com base no número de profissionais da área contábil que estão registrados na empresa do estudo.

Tabela 4 - Despesas variáveis

\begin{tabular}{l|r|r|r}
\hline \multicolumn{1}{c|}{ Impostos } & \multicolumn{1}{c|}{ Julho/18 } & \multicolumn{1}{c|}{ Agosto/18 } & \multicolumn{1}{c}{ Setembro/18 } \\
\hline Simples & $8.916,58$ & $9.397,79$ & $8.447,05$ \\
\hline ISS Fixo & 285,96 & 285,96 & 285,96 \\
\hline Total & $\mathbf{9 . 2 0 2 , 5 4}$ & $\mathbf{9 . 6 8 3 , 7 5}$ & $\mathbf{8 . 7 3 3 , 0 1}$ \\
\hline
\end{tabular}

Fonte: Elaborada pelos autores (2019).

Para os escritórios de contabilidade, o ISS não é pago dentro da guia do Simples Nacional, pois o mesmo já paga o ISS fixo para o município da sua sede de acordo com o número de profissionais registrados no contrato social da empresa.

\subsection{Aplicação do TDABC}

O método permite chegar ao custo por minuto, ou por hora de trabalho por colaborador, e ainda analisa as atividades que são realizadas e o tempo que é necessário para realizar cada uma das atividades. Pode-se dizer que o método TDABC pode auxiliar nas tomadas de decisóes, referente aos departamentos 
da empresa. E ele pode mensurar com exatidão o custo de cada um dos procedimentos das atividades, bem como o custo hora de um colaborador. Estas informaçôes são importantes para a empresa, pois desta forma os colaboradores podem ser aproveitados de uma forma que gere um custo menor para a empresa fazendo com que, consequentemente, a empresa gere mais lucro.

Fez-se uma coleta de dados na empresa prestadora de serviços contábeis, referente ao tempo de serviço por cliente de junho, julho e agosto, com o intuito de identificar e separar os custos da empresa.

A análise dos resultados permitiu gerar e elaborar quadros e tabelas com as informaçóes relacionadas à empresa do estudo. Todas estas informaçóes correspondem a um cálculo da média dos meses de junho, julho e agosto do corrente ano.

O método TDABC requer somente duas variáveis para a sua aplicação que são os custos totais da empresa para a realização das atividades e o tempo necessário para o seu desempenho.

Como mencionado na obra de Consorte, Umpierre e Bruchez (2015), o método de custeio TDABC permite que se obtenham as informaçóes que não poderiam ser encontradas se utilizasse outro dos métodos de custeio. Com ele é possível saber o custo exato de cada um dos departamentos da empresa.

O primeiro passo a ser realizado no método de custeio TDABC é a identificação das atividades nos departamentos da empresa. Com o intuito de garantir que o mapeamento das atividades seja realizado de forma correta e adequada, devem ser apresentados os departamentos e as suas atividades da prestação de serviços.

O departamento contábil do escritório é subdivido nas atividades de lançamentos contábeis, onde os colaboradores recebem as duplicatas pagas e recebidas, os impostos pagos, extratos e demais despesas a serem lançadas na contabilidade. Após os lançamentos serem efetuados, é necessário fazer a conferência dos mesmos.

Em seguida, todos os documentos anteriormente lançados são arquivados e guardados nas caixas dos respectivos clientes no arquivo morto. Ainda tem o procedimento de encerramento contábil, que é o fechamento do balancete mensal. E para alguns clientes tem a obrigatoriedade da entrega de obrigaçóes acessórias, como por exemplo a DCTF mensal, a ECF anual, a DIRF anual e a ECD anual.

O departamento trabalha eventualmente auxiliando os clientes em serviços extras, como licitaçóes, onde preenche os formulários, emite as certidóes de regularidade. Conta com auxilio nas renovações de alvará, contas bancárias, certificados digitais e licenciamentos. Faz a elaboração de planilhas financeiras para entidades (prestação de contas), que devem ser enviadas para prefeituras do município que as compete, ou ao órgão responsável.

O departamento fiscal é subdividido nas seguintes atividades: o atendimento a clientes na recepção, onde fazem a cobrança dos honorários, ajudam a sanar as dúvidas em relação a assuntos do departamento, ou direcionam a pessoa para o colaborador que o ajudará; e conta também com a atividade de lançamento das notas fiscais de entrada, saída ou de prestação de serviços.

Realiza-se a importação das notas pelo arquivo XML que os clientes enviam ou ainda que os colaboradores buscam no sistema que o escritório paga para resgatar todas as notas fiscais que são emitidas 
para os clientes. Após o procedimento de lançamento e importação é feita a conferência das notas, a conferência dos lançamentos de CFOP e das contas contábeis.

Após efetuada a conferência é realizado o encerramento fiscal em que são emitidos os livros fiscais de entrada, saída, serviços prestados e apuração de ICMS. Em seguida são realizadas as apuraçóes e emissões dos impostos, que são: o Simples Nacional, PIS, COFINS, ISS, ICMS. Se o cliente for do lucro real, ou presumido, ainda tem a apuraçáo do IRPJ e da CSLL.

O departamento de recursos humanos $(\mathrm{RH})$, é subdivido nas atividades de processo de admissão de funcionários em que, depois da obrigatoriedade do eSocial, antes da realização da admissão é feita a qualificação e os exames. $\mathrm{O}$ processo de rescisão de funcionários inclui os procedimentos de fazer o pedido do exame demissional, o preenchimento dos documentos para solicitar o seguro desemprego e o resgate do FGTS no caso de o funcionário ser demitido.

Outro procedimento de responsabilidade do departamento de RH é a emissão do recibo de férias e o cálculo de férias. E também o cálculo e conferência das horas dos pontos dos funcionários, para depois poder calcular e emitir as folhas de pagamento dos salários. Após realizar o cálculo das folhas de pagamento é necessário calcular os encargos como o FGTS, INSS, IR sobre folha, sindicatos.

Por fim devem ser realizadas as conferências tanto das folhas como dos encargos para cada cliente. Realizar o procedimento de gerar o arquivo para a importação da folha de pagamento do seu sistema para enviar ao departamento contábil realizar a importação.

\subsubsection{Mão de obra aplicada nas atividades}

A empresa é dividida em departamentos, e os colaboradores executam somente as atividades relacionadas ao departamento onde estão empregados. Exemplo: os colaboradores do departamento fiscal somente são responsabilizados por assuntos e atividades pertinentes a este departamento, não devendo responder por outro departamento.

Tabela 5 - Colaboradores por departamento

\begin{tabular}{l|c}
\hline \multicolumn{1}{c|}{ Departamentos } & $\mathbf{N}^{0}$ de funcionários \\
\hline Contábil & 2 \\
\hline RH & 3 \\
\hline Fiscal & 3 \\
\hline Total & $\mathbf{8}$ \\
\hline
\end{tabular}

Fonte: Elaborada pelos Autores (2019).

Com o auxílio da Tabela 5 pode-se verificar que o departamento Contábil conta com dois colaboradores, enquanto os departamentos de RH e Fiscal contam com três colaboradores. Ainda há as duas sócias proprietárias, que fazem um trabalho externo, auxiliando os clientes de forma geral, porém fora da sede do escritório. 


\subsubsection{Tempo de realização das atividades}

Para a análise do tempo de realização das atividades de cada departamento foram selecionados dez clientes de forma aleatória, com base nas diferentes características e por ser os que possuem maior diversidade de demandas. Conforme o Quadro 2, demonstra-se cada uma das características e também o regime tributário de cada um.

Quadro 2 - Características dos Clientes

\begin{tabular}{|c|c|c|}
\hline Cliente & Tributação & Características \\
\hline 1 & $\begin{array}{c}\text { Lucro } \\
\text { Real }\end{array}$ & $\begin{array}{l}\text { Empresa de comércio de hortifrúti, produtos alimentícios e carnes. Com } \\
\text { movimentação elevada nos setores contábil e fiscal, movimentação baixa no setor } \\
\text { de RH, possui } 4 \text { funcionários. }\end{array}$ \\
\hline 2 & $\begin{array}{l}\text { Simples } \\
\text { Nacional }\end{array}$ & $\begin{array}{l}\text { Empresa de comércio de materiais hidráulicos e de construção em geral, possui } \\
\text { baixa movimentação no setor de RH, com } 6 \text { funcionários, porém nos setores contábil } \\
\text { e fiscal a movimentação é elevada. }\end{array}$ \\
\hline 3 & $\begin{array}{l}\text { Lucro } \\
\text { Presumido }\end{array}$ & $\begin{array}{l}\text { Empresa de fabricação e comércio de conservas de legumes e frutas, possui elevada } \\
\text { movimentação nos setores de RH, Contábil e Fiscal. Seu corpo de colaboradores é } \\
\text { composto por } 36 \text { funcionários. }\end{array}$ \\
\hline 4 & $\begin{array}{l}\text { Simples/ } \\
\text { Presumido }\end{array}$ & $\begin{array}{l}\text { Empresa de fabricação e comércio de churrasqueiras elétricas (rotativas) e de } \\
\text { equipamentos para churrasqueiras, empresa com elevada movimentação nos } \\
\text { setores Fiscal e Contábil, e com baixa movimentação no setor de RH, possui } 17 \\
\text { funcionários. }\end{array}$ \\
\hline 5 & $\begin{array}{c}\text { Lucro } \\
\text { Real }\end{array}$ & $\begin{array}{l}\text { Empresa de exportação de peças para móveis e ferramentas, possui } 2 \text { colaboradores, } \\
\text { tem alta movimentação fiscal e contábil. }\end{array}$ \\
\hline 6 & $\begin{array}{l}\text { Simples } \\
\text { Nacional }\end{array}$ & $\begin{array}{l}\text { Empresa da área da construção civil, trabalha em reformas de obras, e em construção } \\
\text { de obras novas. Conta com } 15 \text { funcionários, sua movimentação nos setores Fiscal } \\
\text { e Contábil é baixa. Porém no setor de Recursos Humanos, tem alta movimentação. }\end{array}$ \\
\hline 7 & $\begin{array}{l}\text { Simples } \\
\text { Nacional }\end{array}$ & $\begin{array}{l}\text { Empresa prestadora de serviços de pintura, possui baixa movimentação nos setores } \\
\text { contábil e fiscal. No setor de RH tem elevada movimentação, possui } 20 \text { funcionários. }\end{array}$ \\
\hline 8 & $\begin{array}{l}\text { Lucro } \\
\text { Presumido }\end{array}$ & $\begin{array}{l}\text { Empresa prestadora de serviços de incorporação de imóveis, serviços de engenharia } \\
\text { e de construção e reforma. Possui baixa movimentação no setor Fiscal, e média } \\
\text { movimentação no setor contábil. Já no setor fiscal possui uma alta movimentação, } \\
\text { possuindo } 16 \text { funcionários. }\end{array}$ \\
\hline 9 & $\begin{array}{l}\text { Lucro } \\
\text { Presumido }\end{array}$ & $\begin{array}{l}\text { Empresa de incorporação e construção de empreendimentos imobiliários, possui } \\
\text { alta movimentação nos setores de RH, Contábil e Fiscal. Possui } 31 \text { funcionários. }\end{array}$ \\
\hline 10 & $\begin{array}{c}\text { Lucro } \\
\text { Real }\end{array}$ & $\begin{array}{l}\text { Empresa de comércio, mais precisamente um supermercado, com uma média de } 19 \\
\text { funcionários e uma movimentação alta no setor fiscal e contábil. }\end{array}$ \\
\hline
\end{tabular}

Fonte: Elaborado pelos autores (2019).

Após analisar as características de cada um dos clientes, foi realizado o levantamento do tempo de serviço que os colaboradores utilizam para cada uma delas, separado por departamento. Para obter as informações do tempo utilizado em cada um dos departamentos, para realizar as atividades, foram elaboradas planilhas com os dez clientes descritos, onde os colaboradores deveriam anotar o tempo de início e término das atividades.

Nesta tabela os colaboradores deveriam ter realizado as anotações de cada uma das atividades do seu departamento. Como exemplo: no contábil anotar qual seria o tempo de lançamento das duplicatas e impostos, separadamente das demais atividades. Porém, não foi possível realizar este procedimento 
desta maneira. Foi então relacionado o tempo total utilizado para cada cliente, por departamento. Este levantamento, que é demonstrado na Tabela 6, também foi realizado nos três meses (junho, julho e agosto), após foi calculada a média em minutos.

Pode-se perceber que os clientes selecionados para o estudo, realmente diferem de forma relevante quanto ao tempo utilizado para a prestação dos serviços de cada um dos departamentos. É possível perceber que alguns demandam mais e outros menos minutos de trabalho.

Tabela 6 - Cálculo dos minutos trabalhados por cliente

\begin{tabular}{c|c|c|c}
\hline Cliente & Fiscal & Contábil & RH \\
\hline 1 & 755 Minutos & 124 Minutos & 24 Minutos \\
\hline 2 & 917 Minutos & 109 Minutos & 31 Minutos \\
\hline 3 & 902 Minutos & 309 Minutos & 133 Minutos \\
\hline 4 & 1023 Minutos & 405 Minutos & 44 Minutos \\
\hline 5 & 527 Minutos & 113 Minutos & 20 Minutos \\
\hline 6 & 204 Minutos & 193 Minutos & 50 Minutos \\
\hline 7 & 13 Minutos & 76 Minutos & 329 Minutos \\
\hline 8 & 27 Minutos & 65 Minutos & 314 Minutos \\
\hline 9 & 62 Minutos & 210 Minutos & 159 Minutos \\
\hline 10 & 159 Minutos & 840 Minutos & 256 Minutos \\
\hline
\end{tabular}

Fonte: Elaborada pelos autores (2019).

\subsubsection{Cálculo e rateio dos custos fixos}

Foram coletados os custos fixos que a empresa possui por departamento, que podem ser entendidos como custos ou recursos que são consumidos para a realização da prestação dos serviços. Os custos indiretos foram rateados utilizando como direcionador o percentual de participação dos custos salariais por departamento. De acordo com os salários líquidos somados aos encargos de cada departamento, foram apurados os percentuais de equivalência de cada departamento. Com base nestes percentuais foram rateados os custos indiretos da empresa. Conforme demonstrado na Tabela 7, os custos do departamento contábil equivalem a $40 \%$ do total, enquanto o fiscal tem participação de $27 \%$ e RH de $33 \%$.

Tabela 7 - Cálculo e rateio dos custos indiretos

\begin{tabular}{l|r|r|r|r}
\hline \multicolumn{1}{c|}{ Recursos } & \multicolumn{1}{c|}{ Contábil } & \multicolumn{1}{c|}{ Fiscal } & \multicolumn{1}{c}{ RH } & \multicolumn{1}{c}{ Total } \\
\hline Pró-labore & $1.323,20$ & 893,16 & $1.091,64$ & $3.308,00$ \\
\hline Aluguel & $1.200,00$ & 810,00 & 990,00 & $3.000,00$ \\
\hline Energia Elétrica & 306,82 & 207,10 & 253,13 & 767,05 \\
\hline Telefone & 424,73 & 286,70 & 350,41 & $1.061,83$ \\
\hline Material de Escritório & $1.023,33$ & 690,75 & 844,25 & $2.558,33$ \\
\hline Despesas Gerais & 901,18 & 608,30 & 743,47 & $2.252,95$ \\
\hline Treinamento/Consultoria & 580,80 & 392,04 & 479,16 & $1.452,00$ \\
\hline Despesas com internet & 80,80 & 54,54 & 66,66 & 202,00 \\
\hline Sistemas & 839,99 & 566,99 & 692,99 & $2.099,98$ \\
\hline
\end{tabular}




\begin{tabular}{l|r|r|r|r}
\hline Condomínio & 312,00 & 210,60 & 257,40 & 780,00 \\
\hline Limpeza & 112,00 & 75,60 & 92,40 & 280,00 \\
\hline Depreciação & 655,71 & 442,60 & 540,96 & $1.639,27$ \\
\hline Táxi & 127,33 & 85,95 & 105,05 & 318,33 \\
\hline Total & $\mathbf{7 . 8 8 7 , 9 0}$ & $\mathbf{5 . 3 2 4 , 3 3}$ & $\mathbf{6 . 5 0 7 , 5 2}$ & $\mathbf{1 9 . 7 1 9 , 7 6}$ \\
\hline
\end{tabular}

Fonte: Elaborada pelos autores (2019).

Pode se perceber os valores de custos indiretos de cada um dos departamentos, uma vez que o departamento contábil teve maior percentual com base no rateio realizado através dos custos salariais, e o departamento com menor custo fixo foi o departamento fiscal. Pode se chegar à conclusão de que o departamento fiscal ficou com menor custo, por ter sofrido uma demissáo durante o período analisado.

\subsubsection{Taxa do custo da capacidade dos departamentos}

Com os custos indiretos e diretos calculados, foi possível chegar ao total dos custos por departamento, onde está demonstrado na Tabela 8 o total para cada um deles.

Tabela 8 - Identificação dos custos totais por departamento

\begin{tabular}{l|r|r|r|r}
\hline \multicolumn{1}{c|}{ Custos } & \multicolumn{1}{c|}{ Contábil } & \multicolumn{1}{c|}{ Fiscal } & \multicolumn{1}{c}{ RH } & \multicolumn{1}{c}{ Total } \\
\hline Custos Diretos & $10.960,52$ & $7.590,15$ & $9.050,49$ & $27.601,16$ \\
\hline Custos Indiretos & $7.887,90$ & $5.324,33$ & $6.507,52$ & $19.719,76$ \\
\hline Total & $\mathbf{1 8 . 8 4 8 , 4 2}$ & $\mathbf{1 2 . 9 1 4 , 4 9}$ & $\mathbf{1 5 . 5 5 8 , 0 1}$ & $\mathbf{4 7 . 3 2 0 , 9 2}$ \\
\hline
\end{tabular}

Fonte: Elaborada pelos autores (2019).

O segundo passo, após ter identificado as atividades da empresa, saber qual o custo total de cada um dos departamentos e ter calculado capacidade prática de cada colaborador, é calcular a taxa de custo da capacidade por minuto. Para realizar este cálculo é utilizada a fórmula criada por Kaplan e Anderson (2007).

\subsubsection{Taxa do custo da capacidade}

Conforme trazem em sua obra Kaplan e Anderson (2007), o método TDABC utiliza o tempo como o principal direcionador dos custos, pois as atividades executadas pela empresa utilizam o tempo como seu insumo. Para tanto, os autores sugerem que cada empresa determine e aplique seus próprios parâmetros de acordo com seu estado, cidade e país, das estimativas para calcular o tempo em média de trabalho de um mês. 
Método de Custeio Baseado em Atividades e Tempo...

Caroline Fabrin | Marcelo Juarez Vizzotto | Lauri Paulus

Tabela 9 - Capacidade prática de cada colaborador

\begin{tabular}{l|r}
\hline \multicolumn{1}{c|}{ Capacidade de trabalho } & \multicolumn{1}{c}{ Quantidade } \\
\hline (=) Número de dias por ano & 365 dias \\
\hline (-) Finais de semana & 104 dias \\
\hline (-) Feriados & 11 dias \\
\hline (-) Férias & 30 dias \\
\hline (-) Faltas & 2 dias \\
\hline (=) Capacidade anual & 218 dias \\
\hline (-) número de meses por ano & 12 meses \\
\hline (=) Capacidade mensal & 18 dias \\
\hline (x) Jornada de trabalho diária & 528 minutos \\
\hline (-) Pausas e intervalos & 60 minutos \\
\hline (=) Capacidade diária & 468 minutos \\
\hline (=) Capacidade mensal & $\mathbf{8 . 4 2 4}$ minutos \\
\hline
\end{tabular}

Fonte: Adaptada de Kaplan e Anderson (2007).

A Tabela 9 demonstra o terceiro passo, a estimativa de tempo trabalhado calculado sobre a empresa do presente estudo.

Os dados sobre os dias trabalhados, finais de semana, bem como os horários utilizados para a adaptação e elaboraçáo da Tabela 9, foram usados da empresa do estudo; e referente aos feriados foram utilizados referentes ao município sede da empresa. Para o cálculo das faltas e das pausas e intervalos, foi feito um controle médio de acordo com as anotações que os colaboradores fazem dos horários de faltas e saídas.

Kaplan e Anderson (2007) presumem que a capacidade real de cada colaborador seja de 80\%, e que $20 \%$ seria o tempo consumido entre chegadas e saídas, intervalos, conversas ou reunióes. Portanto, para a empresa do estudo foram calculados os tempos entre as chegadas e saídas, os intervalos para lanches e também um tempo reservado para conversas que não tratam das atividades desenvolvidas aos clientes.

A seguir apresenta-se a fórmula adaptada de Kaplan e Anderson (2007), utilizada para chegar à taxa de custo da capacidade, onde aponta o custo em reais por minuto. Após termos o cálculo dos custos por departamento rateado e a capacidade prática de cada colaborador por departamento, aplica-se esta formula e encontra-se qual o custo em reais de cada um dos departamentos da empresa.

A Tabela 10 apresenta a capacidade prática calculada em minutos por departamento, onde o cálculo foi elaborado com base no número de colaboradores de cada um dos departamentos. Citando como exemplo o contábil: são dois colaboradores vezes a capacidade $(2$ x 8.424=16.848).

Tabela 10 - Capacidade prática por departamento

\begin{tabular}{l|r}
\hline \multicolumn{1}{c|}{ Departamentos } & \multicolumn{1}{c}{ Capacidade em minutos } \\
\hline Contábil & 16.848 \\
\hline Fiscal & 25.272 \\
\hline RH & 25.272 \\
\hline Total & $\mathbf{6 7 . 3 9 2}$ \\
\hline
\end{tabular}

Fonte: Elaborada pelos autores (2019). 
A Tabela 11 demonstra o cálculo realizado com base na fórmula da taxa de custo da capacidade por departamento, onde foi utilizado o custo de cada departamento (custo fixo mais custo salarial), dividido pela capacidade prática em minutos (que foi calculada de 8.424), vezes o número de colaboradores por departamento (dois para o contábil, três para o fiscal e três para o $\mathrm{RH}$ ).

O quarto passo é calcular o total da taxa de custos da capacidade por minuto, por departamento. Obteve-se um total de R \$ 1,12 para o departamento contábil, R \$ 0,51 para o fiscal e R \$ 0,62 para o RH. Agora com a variável do custo por minuto de cada atividade definida é possível realizar o cálculo do custo total por cliente, com base no tempo utilizado para realizar todas as atividades da empresa.

Tabela 11 - Taxa de custo da capacidade

\begin{tabular}{l|r|r|r|r}
\hline \multicolumn{1}{c|}{ Fatores } & \multicolumn{1}{c|}{ Contábil } & \multicolumn{1}{c|}{ Fiscal } & \multicolumn{1}{c}{ RH } & \multicolumn{1}{c}{ Total } \\
\hline Custo da Capacidade Fornecida $(\mathrm{R} \$)$ & $18.848,42$ & $12.914,49$ & $15.558,01$ & $47.320,91$ \\
\hline Capacidade Prática (minutos) & 16.848 & 25.272 & 25.272 & 67.393 \\
\hline $\begin{array}{l}\text { Taxa de Custo da Capacidade (R\$/ } \\
\text { minutos) em R\$ }\end{array}$ & $\mathbf{1 , 1 2}$ & $\mathbf{0 , 5 1}$ & $\mathbf{0 , 6 2}$ & \\
\hline
\end{tabular}

Fonte: Elaborada pelos autores (2019).

A Tabela 12 demonstra a quantidade de horas trabalhadas por departamento, para os dez clientes do estudo, e demonstra também o valor do custo por minuto. Esse valor foi encontrado com base no cálculo feito da taxa do custo da capacidade por minuto, calculado a partir do custo da capacidade fornecida dividido pela capacidade prática.

Tabela 12 - Quantidade de horas trabalhadas/taxa de capacidade prática

\begin{tabular}{c|c|c|c|c|c|c}
\hline Cliente & Fiscal & $\begin{array}{c}\text { Valor do } \\
\text { minuto em } \\
\mathbf{R S}\end{array}$ & Contábil & $\begin{array}{c}\text { Valor do } \\
\text { minuto em } \\
\mathbf{R S}\end{array}$ & RH & $\begin{array}{c}\text { Valor do } \\
\text { minuto em } \\
\text { R\$ }\end{array}$ \\
\hline 1 & $755 \mathrm{~min}$ & 0,51 & $124 \mathrm{~min}$ & 1,12 & $24 \mathrm{~min}$ & 0,62 \\
\hline 2 & $917 \mathrm{~min}$ & 0,51 & $109 \mathrm{~min}$ & 1,12 & $31 \mathrm{~min}$ & 0,62 \\
\hline 3 & $902 \mathrm{~min}$ & 0,51 & $309 \mathrm{~min}$ & 1,12 & $133 \mathrm{~min}$ & 0,62 \\
\hline 4 & $1.023 \mathrm{~min}$ & 0,51 & $405 \mathrm{~min}$ & 1,12 & $44 \mathrm{~min}$ & 0,62 \\
\hline 5 & $527 \mathrm{~min}$ & 0,51 & $113 \mathrm{~min}$ & 1,12 & $20 \mathrm{~min}$ & 0,62 \\
\hline 6 & $204 \mathrm{~min}$ & 0,51 & $193 \mathrm{~min}$ & 1,12 & $50 \mathrm{~min}$ & 0,62 \\
\hline 7 & $13 \mathrm{~min}$ & 0,51 & $76 \mathrm{~min}$ & 1,12 & $329 \mathrm{~min}$ & 0,62 \\
\hline 8 & $27 \mathrm{~min}$ & 0,51 & $65 \mathrm{~min}$ & 1,12 & $314 \mathrm{~min}$ & 0,62 \\
\hline 9 & $62 \mathrm{~min}$ & 0,51 & $210 \mathrm{~min}$ & 1,12 & $159 \mathrm{~min}$ & 0,62 \\
\hline 10 & $159 \mathrm{~min}$ & 0,51 & $840 \mathrm{~min}$ & 1,12 & $256 \mathrm{~min}$ & 0,62 \\
\hline
\end{tabular}

Fonte: Elaborada pelos autores (2019).

Depois de todos os cálculos realizados, cálculo da capacidade prática por colaborador, cálculo dos custos fixos e salariais de cada departamento, é possível chegar ao custo mensal por cliente e por departamento. Nesse último é feito o seguinte cálculo: a taxa da capacidade por minuto vezes o tempo utilizado em cada departamento para a realização dos procedimentos.

Por exemplo, o departamento contábil utiliza 124 minutos para realizar todos os seus procedimentos no cliente 1 , portanto, 124 x 1,12 (taxa da capacidade por minuto), obtém-se o resultado de $\mathrm{R} \$ 138,88$ 
de custo. Depois calcula-se o custo total dos clientes por mês. A seguir, na Tabela 13, apresenta-se a demonstração:

Tabela 13 - Custo total por cliente

\begin{tabular}{c|r|r|r|r}
\hline Cliente & \multicolumn{1}{|c|}{ Fiscal } & \multicolumn{1}{c|}{ Contábil } & \multicolumn{1}{c}{ RH } & \multicolumn{1}{c}{$\begin{array}{c}\text { Total por } \\
\text { cliente }\end{array}$} \\
\hline 1 & 383,05 & 138,88 & 14,88 & 538,81 \\
\hline 2 & 467,67 & 122,08 & 19,22 & 608,97 \\
\hline 3 & 460,02 & 346,08 & 82,46 & 888,56 \\
\hline 4 & 521,73 & 453,60 & 27,28 & $1.002,61$ \\
\hline 5 & 268,77 & 126,56 & 12,4 & 407,73 \\
\hline 6 & 104,04 & 216,16 & 31,00 & 351,20 \\
\hline 7 & 6,63 & 85,12 & 203,98 & 295,73 \\
\hline 8 & 13,77 & 72,80 & 194,68 & 281,25 \\
\hline 9 & 31,62 & 235,20 & 95,58 & 365,40 \\
\hline 10 & 81,09 & 940,80 & 158,72 & $1.180,61$ \\
\hline Total & $2.340,39$ & $2.737,28$ & 843,20 & $5.920,87$ \\
\hline
\end{tabular}

Fonte: Elaborada pelos autores (2019).

A Tabela 14 apresenta o valor dos honorários de cada um dos clientes selecionados para o estudo. A empresa, que náo possui um método de custeio para chegar no custo que gera com cada um deles, tem como base o cálculo dos honorários de clientes mais antigos. Cada cliente novo é comparado pelo seu porte, número de funcionários e quantidade de notas emitidas.

Tabela 14 - Honorários por cliente

\begin{tabular}{c|r}
\hline Cliente & Honorários (R\$) \\
\hline 1 & $1.192,50$ \\
\hline 2 & $1.670,00$ \\
\hline 3 & $4.000,00$ \\
\hline 4 & $1.908,00$ \\
\hline 5 & $1.500,00$ \\
\hline 6 & $1.545,00$ \\
\hline 7 & 954,00 \\
\hline 8 & 635,00 \\
\hline 9 & $3.339,00$ \\
\hline 10 & $3.100,00$ \\
\hline
\end{tabular}

Fonte: Elaborada pelos autores (2019).

Com o valor dos honorários por cliente definido na tabela anterior e o custo por cliente conhecido após o cálculo na Tabela 14, é possível conhecer o resultado que cada cliente resulta para a empresa do estudo.

Como demonstra a Tabela 15, o cliente que mais gera resultado para a empresa é o cliente 3. Tratase de uma empresa de fabricação e comércio de conservas, onde a mesma tem elevada movimentação 
de trabalho nos três departamentos do escritório contábil. E o cliente que menos gera resultado é o de número 8, do ramo de serviços de engenharia, construção civil e reformas.

Tabela 15 - Resultado por cliente

\begin{tabular}{c|r|r|r}
\hline Empresa & Honorários (R\$) & Custo (R\$) & \multicolumn{1}{|c}{ Resultado (R\$) } \\
\hline 1 & $1.192,50$ & 538,81 & 653,69 \\
\hline 2 & $1.670,00$ & 608,97 & $1.061,03$ \\
\hline 3 & $4.000,00$ & 888,56 & $3.111,44$ \\
\hline 4 & $1.908,00$ & $1.002,61$ & 905,39 \\
\hline 5 & $1.500,00$ & 407,73 & $1.092,27$ \\
\hline 6 & $1.545,00$ & 351,20 & $1.193,80$ \\
\hline 7 & 954,00 & 295,73 & 658,27 \\
\hline 8 & 635,00 & 281,25 & 353,75 \\
\hline 9 & $3.339,00$ & 365,40 & $2.973,60$ \\
\hline 10 & $3.100,00$ & $1.180,61$ & $1.919,39$ \\
\hline
\end{tabular}

Fonte: Elaborada pelos autores (2019).

Depois de analisar os custos que cada um dos dez clientes gera para a empresa prestadora de serviços contábeis, e o valor dos honorários que são cobrados de cada um deles, foi possível demonstrar, na Tabela 15, os resultados que cada cliente oferece. Pode-se perceber que o cliente 3, que possui o valor de honorários mais elevado e o seu custo não é o mais elevado, traz para o escritório o maior resultado. Já o cliente 4 é o que mais utiliza o tempo para execução dos serviços do escritório.

Dessa forma, percebe-se um desequilíbrio nos valores cobrados de honorários. Todavia, ressalta-se que a empresa nunca utilizou qualquer tipo de método de custeio para gerenciar seus dados e chegar no cálculo de quanto cada cliente representa nos seus custos. $\mathrm{O}$ escritório utiliza sempre os dados, para ofertar os serviços a possíveis novos clientes, em meio a orçamentos e se baseando em informaçóes como, por exemplo, saber qual cliente está no escritório a mais tempo, que se equivale a esse novo cliente.

Sendo assim, os custos acabam ficando desproporcionais aos valores de honorários de cada cliente, trazendo resultados desequilibrados em comparação ao nível de trabalho que cada empresa demanda do escritório.

\section{CONSIDERAÇÕES FINAIS}

Após realizar a apuraçáo dos gastos da empresa e do tempo em que os colaboradores utilizavam para realizar as atividades dos clientes, o método TDABC se mostrou adequado para a prestaçáo de serviços contábeis, pois utiliza o tempo como seu principal mensurador do cálculo. Foram analisados todos os processos que o escritório realiza e verificado o tempo necessário para se finalizar o serviço.

Apuraram-se todos os custos fixos e salariais da empresa do estudo chegando ao custo total mensal. Houve a caracterização da empresa, contando um breve relato de sua criação até os dias atuais, trazendo dados também como seu imobilizado e seu quadro de colaboradores, os produtos oferecidos aos clientes e um breve relato do que representa ou compóe cada um dos departamentos do escritório. 
Método de Custeio Baseado em Atividades e Tempo...

Para aplicação do método foi necessário coletar os dados de quanto tempo cada colaborador levaria para começar e terminar a atividade de cada serviço prestado para os dez clientes selecionados do estudo. Dessa forma obteve-se a informação de quanto tempo cada cliente toma sobre os serviços oferecidos.

Com o total de minutos levantados por cliente foi possível realizar os cálculos de custo por minuto e a capacidade prática de cada colaborador, isto é, foi possível calcular o custo que cada cliente gera para o escritório. E assim conseguir encontrar qual o resultado que os mesmos trazem para a empresa.

Detectou-se no estudo que a empresa não utiliza nenhum método de custeio para auxiliar nas tomadas de decisóes sobre os clientes. Corroborando com isto fez-se válido o estudo pela possível facilidade na implantação do método de custeio TDABC.

Conclui-se, portanto, que para a empresa objeto do estudo o método TDABC mostrou-se adequado, pois foi possível determinar os custos para cada um dos procedimentos e atividades da empresa. Vale salientar que, por se tratar de um estudo de caso único, não se deve generalizar os resultados, pois cada empresa possui as suas peculiaridades, e para a definição do método mais adequado para cada empresa é necessário que, para os cálculos, elas sejam levadas em consideração. Cabe ao gestor da empresa objeto do estudo utilizar as informaçóes gerencialmente reavaliando, por exemplo, seus preços de venda.

Assim, gerencialmente este estudo contribui mostrando que a aplicabilidade do método TDABC é simples, podendo ser utilizado em empresas de pequeno e médio porte, sendo prestadoras de serviços ou não. Basta haver uma organização de controle de custos e de atividades. É um método que não requer altos investimentos para sua implementação.

Este estudo limitou-se a ser um estudo de caso e também por ter analisado os dados de um trimestre. Acerca deste tema sugere-se que sejam realizadas pesquisas futuras em empresas de outros ramos de atividade ou ainda em prestação de serviços, que contenham outros produtos. Além do mais, pode-se utilizar um período mais amplo para apuração dos dados.

\section{REFERÊNCIAS}

BORNIA, Antonio Cesar. Análise gerencial de custos: aplicação em empresas modernas. 3. ed. Porto Alegre: Bookman, 2010.

BRASIL. Receita Federal. Tabela de taxas de depreciação de bens do ativo imobilizado. Disponível em: <http://webcache.googleusercontent.com/search?q=cache:Lwr6U6Bku4cJ:normas.receita.fazenda. gov.br/sijut2consulta/anexoOutros.action\%3FidArquivoBinario\%3D36085+\&cd=4\&hl=ptBR\&ct=clnk\&gl=br>. Acesso em: 28 set. 2018.

BRUNI, Adriano Leal; FAMÁ, Rubens. Gestão de custos e formação de preços: com aplicaçóes na calculadora HP. 2. ed. São Paulo: Atlas, 2012.

CERVO, Amado Luiz; BERVIAN, Pedro Alcino; DA SILVA, Roberto. Metodologia científica. 6. ed. São Paulo: Pearson Prentice Hall, 2007. 
CONSORTE, Thiago Rodrigo; UMPIERRE, Marcia Borges; BRUCHÊZ, Adriane. Custeio Baseado em Atividade e Tempo (TDABC) - Estudo de Caso em uma Empresa de Estofados. XV Mostra de Iniciação Cientifica, Pós Graduação, Pesquisa e Extensão. Universidade de Caxias do Sul: SN, nov./dez. 2015.

CORONETTI, Jucimar; BEUREN, Ilse Maria; SOUZA, Marco A. Batista de. Os métodos de custeio utilizados nas maiores indústrias de Santa Catarina. Revista Eletrônica de Gestäo Organizacional, v. 10, n. 02, p. 324-343, maio/ago. 2012. Disponível em: <https://periodicos.ufpe.br/revistas/gestaoorg/issue/ view/1604>. Acesso em: 17 jul. 2018.

CREPALDI, Silvio Aparecido. Curso básico de contabilidade de custos. 5. ed. São Paulo: Atlas, 2010.

GIL, Antonio Carlos. Como elaborar projetos de pesquisa. 6. ed. São Paulo: Atlas S.A., 2017.

GIL, Antonio Carlos. Métodos e técnicas de pesquisa social. 7. ed. São Paulo: Atlas, 2019.

KAPLAN, Robert Samuel; ANDERSON, Steven Robert. Custeio baseado em atividade e tempo. Rio de Janeiro: Elsevier, 2007.

MARTINS, Eliseu. Contabilidade de custos. 11. ed. São Paulo: Atlas, 2018.

MAZZUCO, Miriam A. S.; WRONSKI, Pollyanna G.; ZONATTO, Vinicius C. S. Custeio Baseado em Atividades e Tempo (TDABC): um estudo em uma instituição de ensino superior do sul do estado de Santa Catarina. XXIV Congresso Brasileiro de Custos. Florianópolis/SC. Nov/2017.

MEGLIORINI, Evandir. Custos: análise e gestão. 3. ed. São Paulo: Pearson, 2012.

MICHEL, Maria Helena. Metodologia e pesquisa cientifica em ciências sociais. 3. ed. São Paulo: Atlas, 2014.

NAKAGAWA, Masayuki. ABC: custeio baseado em atividades. 2. ed. São Paulo: Atlas, 2012.

PADOVEZE, Clóvis Luís. Contabilidade de custos: teoria, prática, integração com sistemas de informaçóes (ERP). São Paulo: Cengage Learning, 2013.

RAUPP, F. M.; BEUREN, I. M. Metodologia da pesquisa aplicável às ciências sociais. In: BEUREN, I. M. (Org.). Como elaborar trabalhos monográficos em contabilidade: teoria e prática. 3. ed. São Paulo: Atlas, 2014. p. 76-96.

RODRIGUES, Maria D. N.; PINHO, Ruth C. de S. Sistema de custo baseado na metodologia do custeio TDABC: uma experiência em uma entidade de apoio. Revista Ambiente Contábil. v. 9. n.1. p. 383-396, jan./jun./2017.

SANTOS, Antonio Raimundo dos. Metodologia científica: a construção do conhecimento. 8. ed. Rio de Janeiro: Dpea, 2015. 
Método de Custeio Baseado em Atividades e Tempo...

CHMIDT, Paulo; LEAL, Ricardo da Rosa; SANTOS, José Luiz dos. Proposta de um modelo de rentabilidade de clientes: um estudo de caso de uma empresa da área de alimentos. Revista de Informação Contábil. v. 5, n. 4, p. 26-45, out./dez. 2011.

SEVERINO, Antônio Joaquim. Metodologia do trabalho cientifico. 24. ed. rev. e atual. São Paulo: Cortez, 2018.

THIOLlENT, Michel. Metodologia da pesquisa-ação. 18. ed. São Paulo: Cortez, 2011. 